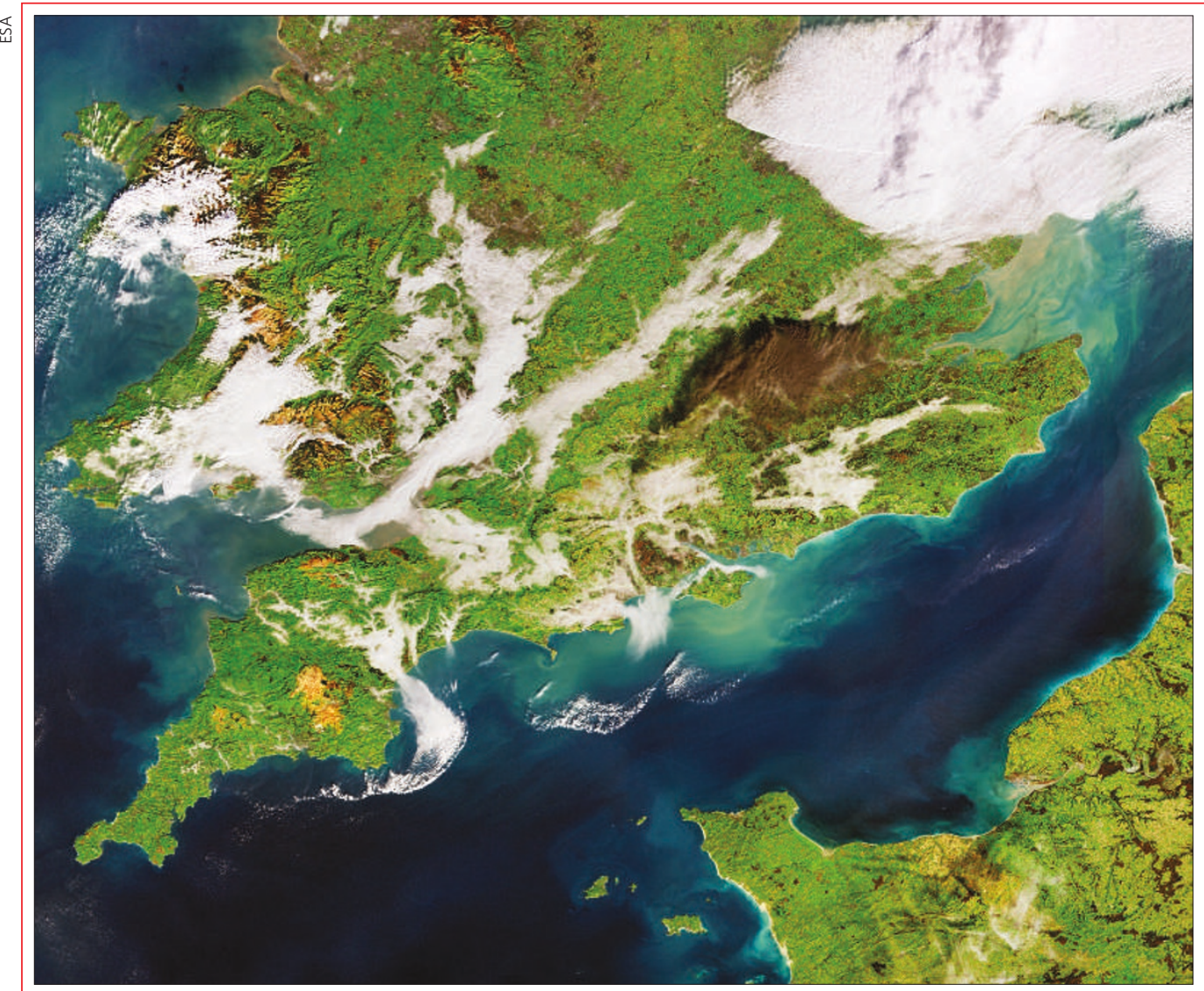

\title{
SNAPSHOT Blot on the landscape
}

Explosions at an oil depot nea London on 11 December created one of Europe's biggest ever industrial fires. This image, taken by the Envisat satellite five hours after the initial blast, shows the resulting plume of smoke - it spans more than $140 \mathrm{~km}$. Up to 270 million litres of fuel were held in the 20 tanks that exploded at the Buncefield site.

Atmospheric scientists flew a plane through the smoke on 12 and 13 December to log pollutants present and measure particle sizes. That should help to refine models for how smoke drifts after fires, volcanoes or nuclear blasts.

But the current plume poses little health or environmental hazard. The scale of the blaze is dwarfed by Kuwaiti oil wells set alight in 1991, when around 80 billion litres of oil burned.

\section{Journal grows suspicious of Vioxx data}

The integrity of a key study of the painkiller Vioxx has been questioned by the New England Journal of Medicine, which published the work in 2000. Vioxx was taken off the market last year because of evidence that it increased patients' risk of having a heart attack or stroke.

In their statement, published online on 8 December, the journal's editors note that three heart attacks in patients taking Vioxx (rofecoxib) were not included in data submitted for a paper about the drug's side effects. The study, sponsored by Vioxx's maker, Merck, compared the drug with the older pain reliever naproxen to see whether it caused fewer gastrointestinal problems. Crucially, the study also documented heart attacks (C. Bombardier et al. N. Engl. J. Med. 343, 1520-1528; 2000).

The journal calculates that the risk of heart attack was 4.25 times higher in the Vioxx group. Had the unreported attacks been included, they would have boosted that figure to 5 , and quashed the original paper's conclusion that Vioxx adversely affected only those already prone to heart trouble (G. D. Curfman,
S. Morrissey and J. M. Drazen N. Engl. J. Med. 353, 2813-2814; 2005).

Merck says that the published paper accurately described the study's results according to an agreed cut-off date for data analysis. The firm reported the extra events to the US Food and Drug Administration (FDA) in 2000.

In 2001, the editors found out about the events from the FDA, and assumed that they had occurred too late to be included. But when Gregory Curfman, the journal's executive editor, made a deposition in Vioxx-related litigation last month, he discovered that at least two of the authors had known about the heart attacks four months before publication.

A leading epidemiologist says that the authors of the study may not have acted wrongly. "If the outcomes truly occurred after the close of the study, then they don't belong in the study," says Brian Strom of the University of Pennsylvania in Philadelphia. Investigators always establish cut-off dates in their research protocols, but do not always publish details of them in their final papers, says Strom.
In this case, an external committee agreed the cut-off date. But the episode raises questions over whether authors should be required to disclose information on significant events that occur after such a date.

The editors have since discovered that other relevant data were deleted from the manuscript two days before it was submitted. "Taken together, these inaccuracies and deletions call into question the integrity of the data on adverse cardiovascular events in this article," the editors write. They call for a correction.

The paper's lead author, Claire Bombardier of the University of Toronto, Canada, has said that she and the other authors - two of whom are Merck employees - are preparing a response to the editors' statement.

Vioxx was a blockbuster drug for New Jersey-based Merck until it was withdrawn after other work found that it could double someone's risk of having a heart attack. Roughly 7,000 lawsuits have been filed against Merck since the drug's withdrawal.

Meredith Wadman 